\title{
Association between root/coronal caries and individual factors in institutionalised elderly using ICDAS severity and activity
}

Margarita Usuga-Vacca' ${ }^{1}$ Dairo Javier Marin-Zuluaga ${ }^{2}$, Jaime Eduardo Castellanos ${ }^{3}$ and Stefania Martignon ${ }^{\text {* }}$

\begin{abstract}
Background: Caries in the elderly has been associated with dependence, oral-health status and -care practices. This cross-sectional study aimed to investigate the association between root/coronal caries and individual factors among institutionalised elderly people in Bogotá, Colombia, using the International Caries Detection and Assessment System severity and activity criteria (ICDAS).
\end{abstract}

Methods: A total of 226 institutionalised elderly were clinically examined for root and coronal caries in 40 institutions. Caries risk was assessed with Cariogram, and demographics, oral health knowledge and practices, oral health-related quality of life and denture-use habits using a questionnaire.

Results: Participants (mean age: $80.1 \pm 9.3$ years; $63.7 \%$ female) presented a mean number of $10.8 \pm 7.3$ teeth and $19.4 \pm 18.8$ exposed root surfaces. Prevalence of Coronal-ICDAS caries experience (C-ICDAS DF) was of 100\% and of $54.4 \%$ for C-ICDAS D; mean number of C-ICDAS DFS was $16.76 \pm 27.36$, with $50.9 \%$ of subjects having $\geq$ one active C-ICDAS DS. Prevalence of Root Caries Index was of $49.1 \%$ and of R-ICDAS DF of 46\%; mean number of R-ICDAS DFS was $2.03 \pm 2.78$, with $40.3 \%$ of subjects having $\geq$ one active R-ICDAS DS. Most individuals had a systemic condition (94.2\%) and required oral-hygiene assistance (58\%). Logistic regression analyses showed significant associations $(p<0.05)$ : for coronal active caries when having over six teeth (OR: 2.7), and for root caries, when having coronal caries (OR: 2.41), being a man (OR: 1.95), and having over 14 teeth (OR: 0.30$)$. Those presenting with > eight exposed root surfaces were 4.04 more likely to have root caries and 2.4 times more likely to have active root caries.

Conclusion: In the institutionalised elderly population in Bogotá significant associations were found, both for the presence as for the activity status of root and coronal caries, with individual clinical factors including coronal caries, exposed root surfaces and number of teeth.

Keywords: Dental caries, Root caries, Elderly, Health behavior, Partial denture, Health-related quality of life

\section{Background}

There is a rapid increase in life expectancy throughout the world. The global population aged $60+$ years was 962 million in 2017 and is expected to double by 2050, when it is projected to reach nearly 2.1 billion. The proportion

*Correspondence: martignonstefania@unbosque.edu.co

1 UNICA - Caries Research Unit, Research Department, Universidad El

Bosque, Av. Cra. 9 No. 131 A - 02, 110121 Bogotá, Colombia

Full list of author information is available at the end of the article of older adults in Colombia is expected to increase from 11.6 to $27.5 \%$ during the same period [1]. The more recent National Oral Health Study in Colombia in the elderly (non-institutionalised, 65-79 years) show a high burden of caries experience, with a prevalence of coronal caries experience (DMF) of $96.3 \%$, a mean number of $8.0 \pm 0.1$ present teeth, a prevalence of cavitated root caries lesions (D) of $31.4 \%$, and a RCI of 0.7 [2]. 
Geriatric institutions are a more frequently residence option for the elderly and living in these institutions has been described as a factor associated with a high presence of caries [3, 4]. Higher instances of disability, frailty and dependence are common among institutionalised elderly people $[5,6]$ and are associated with a higher likelihood of having oral health problems, such as dental caries [5, 7]. An increase in the number of retained teeth [7-9] and those with pre-existing root caries lesions, plaque [9-11], coronal caries $[12,13]$, exposed root surfaces [10-14] and hyposalivation [15] and intake of free sugar $[16,17]$ have been described as risk factors for root caries $[16,17]$.

Root Caries Index (RCI) is one of the most frequently used epidemiological indices to measure the root caries experience at the tooth/surface level $[18,19]$. This conventional index quantifies in teeth with exposed roots, the cavitated caries lesions (D) and fillings (F).

For coronal caries, the conventional DMF index has been the most widely used [19]. This includes Decayed (D), Missing (M), and Filled (F) tooth/surfaces, considering for D only caries lesions at a cavitated stage [19].

The International Caries Detection and Assessment System (ICDAS) is a detection and assessment system classifying stages of the caries process based on histological extent and activity (when included). Its caries criteria include besides extensive-stage caries lesions (cavitated deep dentine lesions), moderate- and initial-caries lesions (enamel/superficial dentine and non-cavitated lesions). The Conventional DMF index considers as its D component the extensive (and in some studies also the moderate) caries lesions. Thus ICDAS can be used both to compare with other studies using DMF and in addition can separately incorporate the initial caries lesions to have a wider and more current epidemiological caries profile description [20]. ICDAS can also assess the activity/progression status of the caries lesions. Altogether this information allows for a more accurate local and/or national information needs and facilitates a move from an operative/surgical approach to more non-operative/ preventive treatment of dental caries [20]. Among the elderly, ICDAS has been used for coronal caries for over a decade $[2,21,22]$ and more recently for root caries [13, 22].

The identification of factors associated with root/coronal caries in institutionalised elderly using more sensitive caries criteria and considering the caries lesions' progression status contributes to guide proposals focused on reducing the caries burden in this population. Thus, the aim of this cross-sectional study was to investigate the association between root/coronal caries and individual factors among institutionalised elderly people in Bogotá, Colombia, using the ICDAS severity and activity criteria.

\section{Materials and methods}

This cross-sectional study counted with IRB (012-2016) and followed the STROBE guidelines.

Based on the number of registered geriatric institutions $(n=152)$ [23], the estimated universe number of institutionalized elders is of around 1900. The sample size was calculated with the sample calculation software $1.1^{\circledR}$, based on the epidemiological data of prevalence of caries experience (DMF coronal caries lesions) of of $96.3 \%$ among the elderly obtained from the 2015 National Oral Health Survey [2], anticipating a similar corresponding prevalence and considering a proportion of oversample of $10 \%$ for possible drop-out of subjects during acquisition of clinical exam and surveys. Thus, a sample size of 196 elderly adults were to be included in this study.

The inclusion criteria were adults aged $60+$ years from institutions who did not present reported terminal illness or severe mental impairment in the medical records, nor edentulism, and who agreed to participate by providing a personal/legal representative signed informed consent forms. The exclusion criterion was mouth opening limitation at the time of the clinical examination.

In November 2016, we received from the District Secretary of Social Integration the list of geriatric institutions in the city of Bogota, indicating 152 registered geriatric institutions [23]. From November 2016 to February 2017, we invited all institutions to participate, via post mail and phone calls. Upon acceptance of institutions, for this study subjects $60+$ years old who met the inclusion criteria were personally invited to participate. Subjects from whom we obtained signed consent forms were recruited between March 2017 and May 2018 and data collection was conducted between April 2017 and June 2018.

\section{Clinical examination}

Three examiners who had been previously clinically calibrated for the coronal ICDAS caries visual severity and activity criteria by an ICDAS core examiner (SM) (inter/ intra-examiner reproducibility-weighted Kappa values were $\geq 0.7$ for severity and $\geq 0.6$ for activity) underwent a theoretical and preclinical training and a clinical calibration with natural teeth and elderly patients for root ICDAS caries visual severity and activity criteria by an expert consensus group (MUV, DJMZ, SM), previously discussing and solving difficult cases with the ICDAS core group (inter/intra-examiner reproducibilityweighted Kappa values were $\geq 0.9$ for severity and $\geq 0.7$ for activity).

After assisted tooth brushing, clinical examinations were conducted in the geriatric institution facilities during the morning hours, assessing the subjects in their beds, wheelchairs, or communal sitting areas, using 
headlamps, mouth mirrors, tweezers, ball-ended probes, and cotton rolls. The tooth surfaces were dried with cotton rolls for the examination. Data regarding clinical factors, including use of partial/total dentures; the number of teeth; number of exposed root surfaces, thick plaque, hyposalivation, fillings and caries lesions (coronal/root and active/inactive) were collected. The coronal (C) ICDAS $_{\text {epi }}$-merged assessment of caries lesions (without air drying) included: C-Sound, C-Initial (C-ICDAS 1-2), C-Moderate (C-ICDAS 3-4) and C-Extensive (C-ICDAS 5-6); activity assessment based on: the severity of caries (non-cavitated vs. cavitated), the colour and opacity of the tooth, the tactile sensation and if located in a plaque stagnation area $[15,24]$. The root ( $R$ ) ICDAS assessment of caries lesions (without air drying) included: R-Sound; R-Initial (R-ICDAS 1); R-Moderate (R-ICDAS 2, $\geq 0.5$ to $\leq 2 \mathrm{~mm}$ cavitation) and R-Extensive (R-ICDAS $2,>2 \mathrm{~mm}$ cavitation), along with the activity assessment-based on the same criteria as described earlier but for dentine/ root, and with the inclusion of the contour of the root $[15,24,25]$. In $10 \%$ of the subjects the ICDAS coronal and root caries examinations were repeated.

For the coronal $(\mathrm{C})$ conventional $(\mathrm{Co})$ caries experience, the prevalence/mean number of decayed (D) and filled (F) surfaces (S) (C-Co DFS) was used, where D corresponded to the C-ICDAS-merged-Moderate-Extensive caries lesions; the C-ICDAS-Initial caries lesions were included in the corresponding C-ICDAS caries experience (C-ICDAS DFS).

For the root (R) conventional (Co) caries experience (prevalence/mean number), the RCI was used, which included for its calculation both D (cavitated caries lesions) and F. R-ICDAS-Initial caries lesions were included in the corresponding R-ICDAS caries experience (R-ICDAS DFS).

\section{Questionnaire on individual factors and caries risk classification}

An interview-led questionnaire on individual factors containing 18 items based on validated tools or international guidelines [2, 17, 25-30] was conducted by a trained researcher to assess individual factors (Additional file 1). The 14 general items included in the questionnaire were as follows: demographics (age and gender); condition (presence of hyposalivation); presence of systemic diseases; oral health-related practices (oral hygiene); diet content/frequency habits-assessed by evaluating the daily consumption of free sugars according to the World Health Organization (WHO) guidelines; dental care, related to the last dental visit (reason and time elapsed since); Geriatric/General Oral Health Assessment Index (GOHAI) (to assess the physical functions such as oral hygiene assistance, pain or discomfort, painful sites and use of medication and psychosocial functions such as worry/concern about teeth/gums/dentures and perceived need for dental care). Four additional items were included for those wearing denture, about their oral health-related practices (denture wear time, denture daily cleaning and denture removing before bedtime).

The individual caries risk was calculated using the Cariogram software $[27,29]$ using information from both the questionnaire and the results of the clinical assessment. Other factors from the CariesCare International consensus [15], such as 'Regular preventive-oriented dental care' and 'Symptomatic-driven dental attendance', were assessed using the Cariogram clinical judgement component, where possible. The subjects were classified into high-risk (moderate and high) and low-risk groups.

\section{Statistical analyses}

The categorical variables are expressed in terms of the distribution of absolute and relative frequencies and the continuous variables as measures of central tendency (mean and standard deviations). The subjects' cut off points for both ICDAS coronal and ICDAS root caries were: those without presence and those with presence of ICDAS caries lesions, and those without presence and those with presence of ICDAS active caries lesions. The associations between the individual factors investigated and the outcome measures: presence of $\geq 1$ root caries lesion; $\geq 1$ active root caries lesion; $\geq 1$ coronal caries lesion, and $\geq 1$ active coronal caries lesion, were analyzed using the chi-square test and Fisher's exact test.

In the absence of previously established intrinsic categories the variables "number of teeth in the mouth" and "number of exposed root surfaces" were analyzed using the approach to data analysis by tertiles exposure [31, 32].

The first step of the analyses was crude logistic regression analysis. Subsequently, non-conditional multivariate logistic regression models were used to estimate the odds ratio and $95 \%$ confidence intervals $(\mathrm{CI})$ between the individual variables investigated and the presence of coronal ICDAS/root ICDAS caries lesions, and active coronal ICDAS/active root ICDAS caries lesions, respectively. Furthermore, the relative effect of each individual factor on caries risk was adjusted for age, sex, systemic disease, daily sugar-free frequency intake, thick dental plaque, dental floss use, fluoridated toothpaste use, dental-pain/ discomfort medication/food-type change during the last 3 months.

Final multivariate models were created through stepwise elimination of variables of interest from bivariate analysis. Main independent variables and the covariates were incorporated in the multivariate logistic regression model, if they had a significant $(\mathrm{p}<0.05)$ or marginal association $(p<0.20)$ with the outcome measures, while 
variables considered in the literature or contextually as clinically and biologically relevant were retained. These included age to compare at a national level with corresponding ages [2]; hyposalivation due to its relevance as a caries risk factor [15], as well as daily sugar intake $[15,17]$, and recent concerns due to dental problems as a quality of life indicator [30]. P values of less than 0.05 for associations were considered to indicate statistical significance. SPSS Statistics V.23 (IBM SPSS Statistics) and Stata ${ }^{\circledR} 12$ (StataCorp LLC) were used for statistical analyses.

\section{Results}

Out of 152 geriatric institutions in Bogotá, 52 were not reachable after sending post mail and at least three phone calls, and 60 did not agree to participate in the study. In total, 40 geriatric institutions located in five of the 20 municipalities in Bogotá accepted the invitation (26.3\%). From a total of 468 elderly geriatric-institution residents, 242 were not included (51.7\%): 15 did not agree to participate; 37 were not within the age range; 15 were terminally ill, and 174 were edentulous. The remaining 226 agreed to participate in the study providing signed consent forms and none were excluded at the clinical examination, for a total examined sample of $n=226$. The mean age of the subjects was $80.1 \pm 9.3$ years; $63.7 \%$ were women.

The subjects presented with a mean number of $10.8 \pm 7.3$ teeth (range, 1-28) and a population distribution of 1-6 teeth (35.4\%), 7-14 teeth (30.1\%) and 15-28 teeth $(96.3 \%)$. The mean number of exposed root surfaces was $19.4 \pm 18.8$ (range, 0-96) with a population distribution as follows: $0-8$ exposed surfaces (36.7\%), 9-21 exposed surfaces (29.3\%) and 22-96 exposed surfaces $(34.9 \%)$. The majority $(\mathrm{n}=222 ; 98.7 \%)$ had partial tooth loss $(67.7 \%$ in both jaws and $31 \%$ only in the lower jaw); 30.5\% $(n=69)$ of the subjects wore removable partial dentures $(7.1 \%$ in both jaws, $16.3 \%$ only in the lower jaw and $7.1 \%$ only in the upper jaw). A total of 80 subjects (35.4\%) were edentulous only in one jaw (28.8\% upper jaw and $6.6 \%$ lower jaw), whereas $25.2 \%$ of them wore complete dentures (upper: $22.1 \%$ and lower: $3.1 \%$ ).

The prevalence of C-Co DF was $83.6 \%$ and that of C-Co D was $46.5 \%$, which increased to $54.4 \%$ with the inclusion of Initial C-ICDAS D. The mean number of C-ICDAS-DFS was $16.76 \pm 27.36$ (Initial DS, $0.4 \pm 0.89$; Moderate-Extensive DS, $4.6 \pm 10.5$; and FS, $11.8 \pm 16.4$ ). Around half of the subjects (50.9\%) showed at least one coronal ICDAS active caries lesion with a mean number of $4.7 \pm 9.6$ involved surfaces.

Concerning root caries, the prevalence of RCI root caries was $49.1 \%$, with a mean number of $1.09 \pm 2.24$ involved surfaces. The prevalence of R-ICDAS DF was $46 \%$, and the mean number of R-ICDAS DFS was $2.03 \pm 2.78$ (Initial DS: $0.62 \pm 1.21$; Moderate-Extensive DS: $0.80 \pm 1.67$; and FS: $0.58 \pm 1.23)$. Over a third of the subjects (40.3\%) showed at least one active root ICDAS caries lesion and a mean number of $1.25 \pm 2.44$ involved surfaces.

The repetition of clinical coronal and root ICDAS caries examinations reported perfect intra-examiners' agreement of $78.5 \%$ for coronal ICDAS and of $91.0 \%$ for root ICDAS.

The questionnaire showed that most of the participants had a systemic condition (94.2\%), had last visited the dentist over a year ago (84.1\%) and reported daily free sugar consumption above the recommended level (77.4\%). Furthermore, 58\% of the subjects required assistance to perform oral hygiene. Among those wearing denture $(n=69), 79.7 \%$ used it for $<2$ years, $75.4 \%$ cleaned it at least once a day, with dentifrice/ mouthrinse (97.1\%), and 50.7\% did not remove it before bedtime. Over a third of the population perceived the need for dental care (35.4\%) and reported emergency as the reason for the last dental visit (38.1\%). A small number reported the presence of painful sites in the mouth $(5.3 \%)$ or were diagnosed with hyposalivation (3.1\%).

Table 1 shows with the bivariate model statistical associations between the number of teeth in the mouth and presence of coronal ICDAS/coronal ICDAS active caries lesions, between exposed root surfaces and presence of root ICDAS/root ICDAS active caries lesions and between $1 /$ day-denture cleaning and root ICDAS caries $(p<0.05)$.

Table 2 highlights with the logistic regression model significant associations between having over 6 teeth and coronal ICDAS active caries lesions (OR 2.84; $p<0.05)$ and between having over 8 exposed root surfaces (OR $3.01 ; p<0.05)$ and root ICDAS active caries lesions.

In Table 3, the results of the logistic regression model and the associations between the presence of root ICDAS caries lesions/root ICDAS caries active lesions and the individual variables, including the presence of coronal ICDAS caries lesions and coronal ICDAS active caries lesions.

Those who had coronal caries lesions and were men, were correspondingly 2.41 , and 1.95 times more likely to have root ICDAS caries lesions. Furthermore, those who had over 21 exposed root surfaces were 3.51 times more likely to have root ICDAS caries lesions and 2.39 times more likely to have root ICDAS active caries lesions. Conversely, those who had over 14 teeth were $70 \%$ less likely to have root ICDAS caries lesions. 


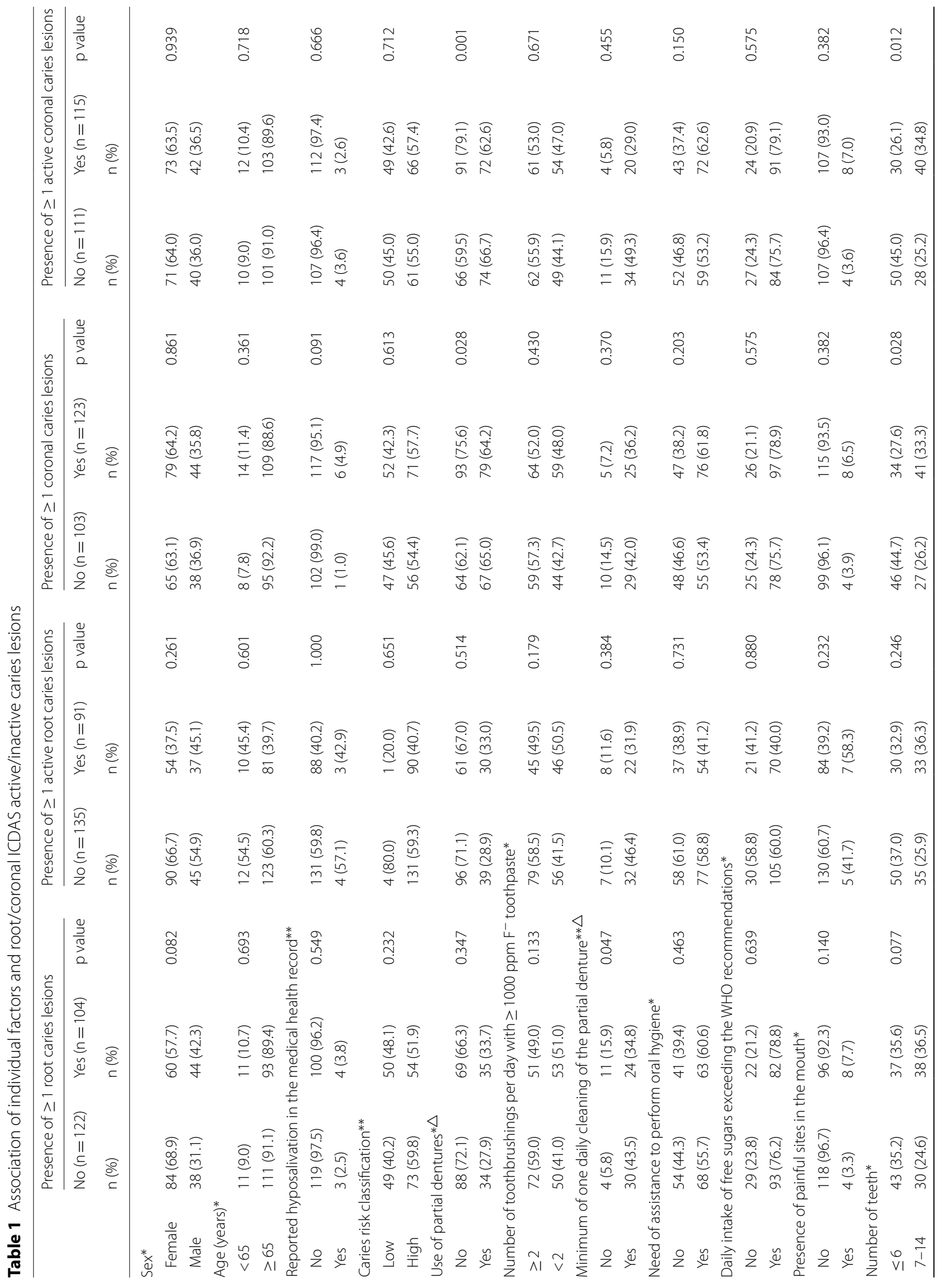




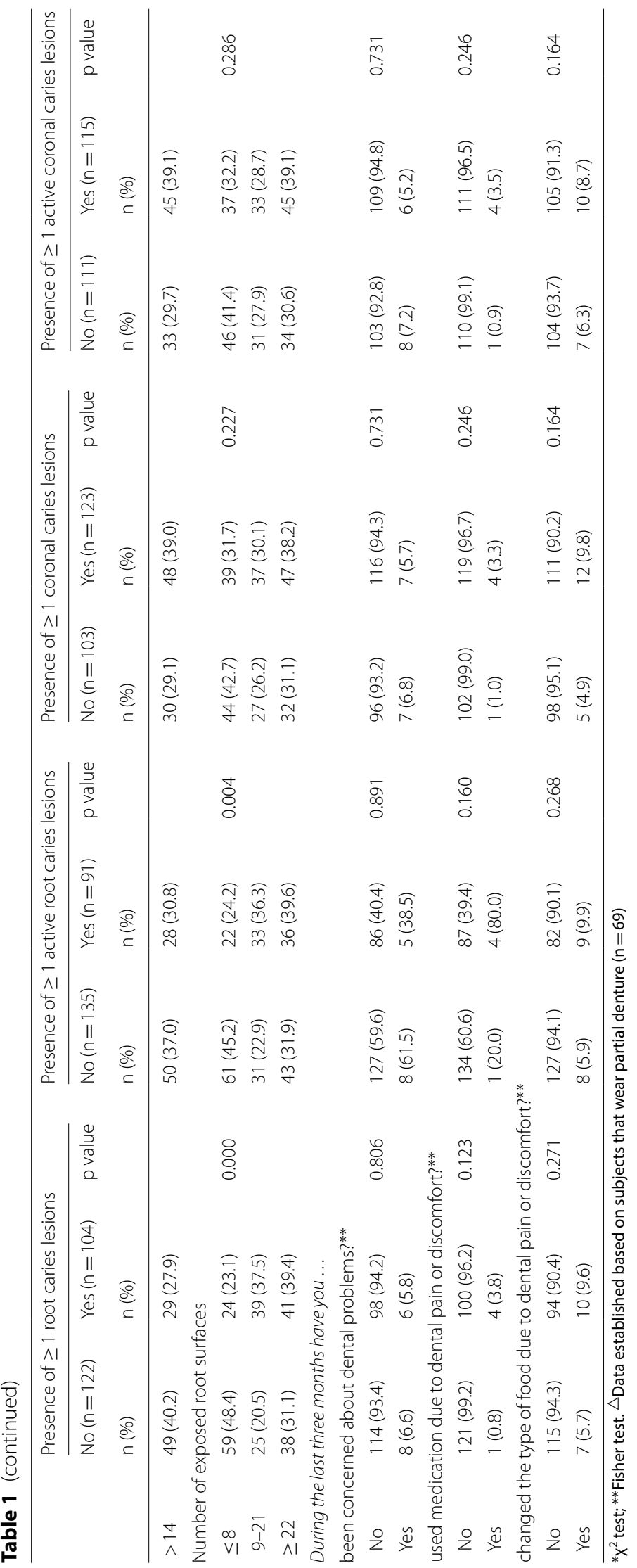


Table 2 Associations between coronal ICDAS active caries lesions, root ICDAS active caries lesions and individual factors

\begin{tabular}{|c|c|c|c|}
\hline \multicolumn{2}{|c|}{$\begin{array}{l}\text { Presence of } \geq 1 \text { active } \\
\text { coronal caries lesions }\end{array}$} & \multicolumn{2}{|c|}{$\begin{array}{l}\text { Presence of } \geq 1 \text { active root } \\
\text { caries lesions }\end{array}$} \\
\hline Crude model & $\begin{array}{l}\text { Adjusted } \\
\text { model }\end{array}$ & Crude model & $\begin{array}{l}\text { Adjusted } \\
\text { model }\end{array}$ \\
\hline OR [95\% Cl] & OR $[95 \% \mathrm{Cl}]$ & OR [95\% Cl] & OR [95\% Cl] \\
\hline
\end{tabular}

\begin{tabular}{lllll}
\hline Sex & & & & \\
Female & 1 [Reference] & 1 [Reference] & 1 [Reference] & 1 [Reference] \\
Male & $1.02[0.57-$ & $0.84[0.46-$ & $1.37[0.76-$ & $1.33[0.72-2.46]$ \\
& $1.82]$ & $1.54]$ & $2.46]$ &
\end{tabular}

Age (years)

$<651$ [Reference] 1 [Reference] 1 [Reference] 1 [Reference]

$\begin{array}{ccccc}\geq 65 & 0.84[0.31- & 1.00[0.37- & 0.79[0.29- & 0.82[0.30-2.26] \\ & 2.25] & 2.73] & 2.14] & \end{array}$

Reported hyposalivation in the medical health record

$$
\begin{array}{lllll}
\text { No } & 1 \text { [Reference] } & 1 \text { [Reference] } & 1 \text { [Reference] } & 1 \text { [Reference] } \\
\text { Yes } & 0.71[0.10- & 0.34[0.05- & 1.11[0.15- & 0.50[0.04-3.38] \\
& 4.34] & 2.16] & 6.77] &
\end{array}
$$

Caries risk classification

$$
\begin{array}{lllll}
\text { Low } & 1 \text { [Reference] } & 1 \text { [Reference] } & 1 \text { [Reference] } & 1 \text { [Reference] } \\
\text { High } & 1.10[0.63- & 1.33[0.63- & 0.73[0.41- & 0.89[0.49-1.59] \\
& 1.93] & 2.00] & 1.30] &
\end{array}
$$

Number of teeth in the mouth

$$
\begin{array}{lllll}
\leq 6 & 1 \text { [Reference] } & 1 \text { [Reference] } & 1 \text { [Reference] } & 1 \text { [Reference] } \\
7-14 & 2.38[1.22- & 2.84[1.31- & 1.57[0.81- & 1.25[0.56-2.77] \\
& 4.61] & 6.15] & 3.02] & \\
>14 & 2.27[1.20- & 2.78[1.27- & 0.93[0.48- & 0.70[0.31-1.59] \\
& 4.30] & 6.09] & 1.78] &
\end{array}
$$

Number of toothbrushings per day with $\geq 1000 \mathrm{ppm} \mathrm{F}^{-}$toothpaste

$<2 \quad 1$ [Reference] 1 [Reference] 1 [Reference] 1 [Reference]

$$
\begin{array}{lcccc}
\geq 2 & 1.16[0.66- & 1.44[0.75- & 1.50[0.85- & 1.42[0.73-2.76] \\
& 2.03] & 2.77] & 2.66]
\end{array}
$$

Daily intake of free sugars exceeding $\mathrm{WHO}$ recommendations

$$
\begin{array}{lllll}
\text { No } & 1 \text { [Reference] } & 1 \text { [Reference] } & 1 \text { [Reference] } & 1 \text { [Reference] } \\
\text { Yes } & 1.21[0.62- & 1.36[0.64- & 0.95[0.48- & 0.75[0.35-1.59] \\
& 2.39] & 2.90] & 1.90] &
\end{array}
$$

\begin{tabular}{|c|c|c|c|c|}
\hline & \multicolumn{2}{|c|}{$\begin{array}{l}\text { Presence of } \geq 1 \text { root caries } \\
\text { lesions }\end{array}$} & \multicolumn{2}{|c|}{$\begin{array}{l}\text { Presence of } \geq 1 \text { active root } \\
\text { caries lesions }\end{array}$} \\
\hline & Crude model & $\begin{array}{l}\text { Adjusted } \\
\text { model }\end{array}$ & Crude model & $\begin{array}{l}\text { Adjusted } \\
\text { model }\end{array}$ \\
\hline & OR $[95 \% \mathrm{Cl}]$ & OR $[95 \% \mathrm{Cl}]$ & OR [95\%Cl] & OR [95\%Cl] \\
\hline \multicolumn{5}{|l|}{$\operatorname{Sex}^{*}$} \\
\hline Female & 1 [Reference] & 1 [Reference] & 1 [Reference] & 1 [Reference] \\
\hline Male & $\begin{array}{l}1.62[0.90- \\
2.90]\end{array}$ & $\begin{array}{l}1.95[1.05- \\
3.61]\end{array}$ & $\begin{array}{l}1.37[0.76- \\
2.46]\end{array}$ & $1.44[0.80-2.60]$ \\
\hline \multicolumn{5}{|c|}{ Age $^{*}$ (years) } \\
\hline$<65$ & 1 [Reference] & 1 [Reference] & 1 [Reference] & 1 [Reference] \\
\hline$\geq 65$ & $\begin{array}{l}0.83[0.31- \\
2.23]\end{array}$ & $\begin{array}{l}0.83[0.31- \\
2.22]\end{array}$ & $\begin{array}{l}0.70[0.29- \\
\quad 2.14]\end{array}$ & $0.81[0.31-2.11]$ \\
\hline \multicolumn{5}{|c|}{ Caries risk classification } \\
\hline Low & 1 [Reference] & 1 [Reference] & 1 [Reference] & 1 [Reference] \\
\hline High & $\begin{array}{l}0.72[0.41- \\
1.27]\end{array}$ & $\begin{array}{l}0.81[0.45- \\
\quad 1.45]\end{array}$ & $\begin{array}{l}0.73[0.41- \\
\quad 1.30]\end{array}$ & $0.82[0.47-1.44]$ \\
\hline \multicolumn{5}{|c|}{ Presence of thick plaque } \\
\hline No & 1 [Reference] & 1 [Reference] & 1 [Reference] & 1 [Reference] \\
\hline $\mathrm{Si}$ & $\begin{array}{l}1.22[0.69- \\
2.15]\end{array}$ & $\begin{array}{l}1.43[0.77- \\
2.64]\end{array}$ & $\begin{array}{l}1.09[0.61- \\
1.95]\end{array}$ & $1.20[0.66-2.1]$ \\
\hline \multicolumn{5}{|c|}{ Partial denture wear $* * \triangle$} \\
\hline No & 1 [Reference] & 1 [Reference] & 1 [Reference] & 1 [Reference] \\
\hline Yes & $\begin{array}{l}1.31[0.71- \\
2.40]\end{array}$ & $\begin{array}{l}1.29[0.67- \\
2.48]\end{array}$ & $\begin{array}{l}1.21[0.65- \\
2.32]\end{array}$ & $1.26[0.66-2.40]$ \\
\hline \multicolumn{5}{|c|}{ Presence of coronal caries lesions } \\
\hline No & 1 [Reference] & 1 [Reference] & $\mathrm{NI}$ & $\mathrm{NI}$ \\
\hline Yes & $\begin{array}{l}2.13[1.20- \\
3.78]\end{array}$ & $\begin{array}{l}2.41[1.33- \\
4.39]\end{array}$ & $\mathrm{NI}$ & $\mathrm{NI}$ \\
\hline
\end{tabular}

Painful sites in the mouth

$$
\begin{array}{lllll}
\text { No } & 1 \text { [Reference] } & 1 \text { [Reference] } & 1 \text { [Reference] } & 1 \text { [Reference] } \\
\text { Yes } & 2.00[0.51- & 1.92[0.45- & 2.16[0.56- & 2.18[0.54-8.75] \\
& 9.32] & 8.15] & 8.92] &
\end{array}
$$

Number of exposed root surfaces

$$
\begin{array}{lllll}
\leq 8 & 1 \text { [Reference] } & 1 \text { [Reference] } & 1 \text { [Reference] } & 1 \text { [Reference] } \\
9-21 & 1.32[0.68- & 1.08[0.54- & 2.95[1.47- & 3.01[1.41-6.40] \\
& 2.54] & 2.48] & 5.89] & \\
>21 & 1.64[0.88- & 1.16[0.54- & 2.32[1.20- & 2.42[1.07-5.46] \\
& 3.06] & 2.48] & 4.48] &
\end{array}
$$

1. The model was also adjusted for other variables without statistical significance and higher $p$ values: Systemic disease, Daily diet frequency intake, Thick dental plaque, Dental floss use, $\mathrm{F}^{-}$toothpaste use, Dental-pain/discomfort medication/ food-type change during last 3 months

2. The variable "Need of assistance to perform oral hygiene" was omitted due to collinearity
Table 3 Associations between root ICDAS caries lesions, root ICDAS active caries lesions and individual factors

Presence of active coronal caries lesions

$$
\begin{array}{lllll}
\text { No } & \mathrm{NI} & \mathrm{NI} & 1 \text { [Reference] } & 1 \text { [Reference] } \\
\text { Yes } & \mathrm{NI} & \mathrm{NI} & 1.64[0.92- & 1.70[0.95-3.04] \\
& & & 2.91] &
\end{array}
$$

Number of teeth in the mouth

$$
\begin{array}{lcccc}
\leq 6 & 1 \text { [Reference] } & 1 \text { [Reference] } & 1 \text { [Reference] } & 1 \text { [Reference] } \\
7-14 & 1.47[0.76- & 0.82[0.37- & 1.57[0.81- & 1.04[0.49-2.24] \\
& 2.81] & 1.80] & 3.00] & \\
>14 & 0.68[0.36- & 0.30[0.13- & 0.92[0.48- & 0.58[0.26-1.28] \\
& 1.29] & 0.70] & 1.78] &
\end{array}
$$

Exposed root surfaces

$$
\begin{array}{lcccc}
\leq 8 & 1 \text { [Reference] } & 1 \text { [Reference] } & 1 \text { [Reference] } & 1 \text { [Reference] } \\
9-21 & 3.83[1.92- & 4.04[1.88- & 2.95[1.47- & 2.82[1.36-5.85] \\
& 7.65] & 8.66] & 5.89] & \\
\geq 22 & 2.65[1.38- & 3.51[1.56- & 2.32[1.20- & 2.39[1.10-5.21] \\
& 5.07] & 7.90] & 4.48] &
\end{array}
$$

${ }^{*} x^{2}$ test; ${ }^{* *}$ Fisher test. $\triangle$ Data established based on subjects that wear partial denture $(\mathrm{n}=69)$. NI not included

\section{Discussion}

In general, most caries occurs in adulthood [33] and the institutionalised population has conditions that make 
them particularly vulnerable to caries [5, 7].

This cross-sectional study was carried out in 40 geriatric institutions in the city of Bogotá, Colombia.

The institutionalised elderly population presented with a high coronal and root caries experience and high frequency of coronal/root ICDAS active caries lesions, which were associated with individual factors. The reported association between coronal caries and root caries $[12,13,34]$ was confirmed in this study with the ICDAS criteria. A stronger correspondent association was found by Hayes et al. [13] (OR 4.50) (Root Decay Filled Surfaces index) and a weaker one (OR 1.03) by Nicolau et al. [8] (DMFS index). These differences might be partly explained by the discrepancies in the indices used.

The significant association between the presence of $>6$ teeth and coronal ICDAS active caries lesions as much as the presence of $>8$ root surfaces and root caries could be explained by the retention of a considerable number of tooth surfaces that increases the likelihood of caries lesions development in coronal and root surfaces, similar to what was reported by different authors $[7,10-13,35]$. This highlights the need for better oral hygiene and biofilm control with fluoridated toothpaste use of at least $1000 \mathrm{ppm} \mathrm{F}^{-}$concentration, as well as sugars control within the elderly [14, 15, 17]. Furthermore, the presence of over 14 remainder teeth was found to be a protective factor for root caries (Table 3). Similar to our findings, Fure and Zickert (1990) reported a negative correlation between root caries and number of remaining teeth [36]. This might be related to the presence of teeth without root exposure [10-13, 35] or, as stated by Fure and Zickert (1990), the presence of teeth with available surfaces is not a sufficient factor for the development of caries [36]. Nevertheless, this finding is contrary to that reported by Ritter et al. [9], who reported a higher association between number of teeth and high incidence of root caries.

In the current study, age was not a factor that could be significantly associated with the presence of caries unlike that reported by Ritter et al. for root caries [9].

The ICDAS caries criteria have scarcely been used for root caries epidemiological studies [22]. The advantages of using these criteria versus the WHO criteria, rely on the inclusion of initial/non-cavitated caries lesions and their activity status, in agreement with the current understanding of the caries process and translating it into a more comprehensive and accurate description of the individuals' and population's caries status [15, 25, 37]. Reporting the caries prevalence using the ICDAS criteria provides a more accurate picture of the caries situation in a population in comparison to using the $\mathrm{DMFT} / \mathrm{S}$ index or the RCI index.
In the study conducted by Christensen et al. [38], they assessed active root caries as lesions located on root surfaces with a soft or leathery texture based on visualtactile examination $[15,24]$. In the current study, we assessed the severity (initial, moderate, and extensive) and activity (active or inactive) of the lesions, in addition to the visual-tactile examinations. This discrimination gave us the possibility to compare the presence of at least one root caries lesion (active/inactive) and at least one active caries lesion with the variables in this study. A 10 times higher prevalence of active caries lesions (40.3\%) was observed in the current study when compared with that from Denmark (3.7\%) [38], which might reflect a less comprehensive national health system because the Colombian study included people $60+$ only a dental appointment every two years including professional prophylaxis, calculus removal and oral hygiene instructions [39]. Another explanation for the difference in the prevalence between the two studies is the fact that we examined only institutionalised elderly people who presented with higher caries root experience $[5,6,40]$. Moreover, we used the root ICDAS caries criteria including different severity scores and active/inactive caries lesions, whereas the study by Christensen et al. [38] included only one type of root caries lesions, namely, the active root caries, defined as localised caries lesions in root surfaces with a soft/leathery texture $[25,38]$.

On average in our study we a higher mean number of remaining teeth (10.8) in comparison to that of 8.0 in the most recent Colombian National Oral Health Study [2]. However, in neither of the two studies the minimum number of 10 teeth per arch to ensure chewing efficiency was achieved [41].

The variable 'Not cleaning the denture at least once a day' was the only one that showed any association with root active caries lesions, possibly indicating better selfcare. Unlike other studies, we did not find any association between caries and the dependence to deliver oral hygiene $[5,6,42]$. Furthermore, similar to the study by Christensen et al. [38], no association between caries and high sugar intake was observed, despite the thorough assessment of daily intake of free sugars was performed based on the WHO recommendations in the present study $[16,17]$.

It is important to note that the results of this study have to be interpreted in the light of institutionalised elderly population. The selected sample represents a higher-than-usual social-economic level within the institutionalised elderly population according to their location within the city in 5 out of 20 municipalities [23]. About one-third of the elderly population from Bogotá live in these five municipalities (33.2\%) [23]. This means that the results cannot be considered fully 
representative of the city of Bogotá. The institutions' rejection to participate in surveys or research projects has been related to low standards of care that exist in many geriatric institutions in Colombia [23]. This is a characteristic of an under-developed country, which helps such institutions to avoid any kind of audit. This issue might also explain the fact that most of the institutions that accepted to participate in this project were located in high social class/income neighbourhoods and that our sample had more teeth than the mean numbers reported in the Colombian population. Nonetheless, the oral health data are still considered to be of value because this is the first study in Colombia to report epidemiological data among institutionalised elderly people. Additionally, severity and activity assessments of both root and coronal caries have been included in this study $[15,37]$, and detailed information about individual factors have been provided [38]. In addition, there should not be an influence of the lack of generalizability in the validity of the biological and social associations between coronal/root caries and individual variables.

Although logistic regressions can overestimate the effect size of statistical associations under a crosssectional design and are considered a limitation of this study, we chose this type of statistical analysis following same design conducted by Christensen et al. [38] who also assessed risk factors and root caries. In addition, in this study the cut off point for classifying individuals with and without coronal/root ICDAS caries lesions and with and without coronal/root ICDAS active caries lesions was very rigorous as examiners were highly trained. The other aspect we considered was the fact that the dichotomization of a continuous or discrete predictor can be used in statistical models to simplify the interpretation [43].

Finally, the classification of elderly into with and without caries groups could guide oral care activities. The coordinators and caregivers of geriatric institutions, with the support of health entities, could apply measures that help reduce the prevalence and development of new caries lesions in the affected group, while keeping the "no cavities" group healthy. Taking into account the challenges that the rapid increase in life expectancy with higher number of retained teeth pose, as well as the raise of other health and quality of life aspects, there is an increasing need of education within the dental profession in the comprehensive understanding of the pathology within other oral and general health aspects, as well as current individualand tooth-surface level caries care guidelines [7, 11, $15,20,25,33,37,44]$.

\section{Conclusions}

In the institutionalised elderly population in Bogotá significant associations were found, both for the presence as for the activity status of root and coronal caries, with individual clinical factors including coronal caries, exposed root surfaces and number of teeth.

\begin{abstract}
Abbreviations
R: Root; RCI: Root Caries Index; D: Decayed; F: Filled; DFT: Decayed, missing, filled teeth; DFS: Decayed, missing, filled surfaces; ICDAS: International Caries Detection and Assessment System; C: Coronal; Co: Coronal conventional; IRB: Institutional Review Board; WHO: World Health Organization; GOHAl: Geriatric/ General Oral Health Assessment Index; DANE: National Administrative Department of Statistics (for its initials in Spanish, Colombia.
\end{abstract}

\section{Supplementary Information}

The online version contains supplementary material available at https://doi. org/10.1186/s12903-021-01520-4.

Additional file 1: Questionnaire on individual factors.

\section{Acknowledgements}

For their logistic assistance we are grateful with Cristhian Cárdenas, Farid Cabrera, Nathaly Chavarría, Natalia Barrantes from UNICA — Caries Research Unit, Universidad El Bosque, and young MinCiencias-2016 researcher Ángela Fonseca-Benitez.

\section{Authors' contributions}

MUV and SM participated in the design and development of the study, the analysis of the data, in writing the paper and reviewing it critically. DJMZ and JEC participated in the study design, the analysis of the data and in critically reviewing the paper. All authors read and approved the final manuscript.

\section{Funding}

The sources of funding for this research were the Ministerio de Ciencia, Tecnología e Innovación (Minciencias) - Department of Science, Technology, and Innovation (Grant Nr. 744, 2016), and the Research Department, Universidad El Bosque. Minciencias did not participate in the design of the study, collection, analysis, and interpretation of data or in the writing the manuscript.

\section{Availability of data and materials}

The datasets used and/or analysed during the current study are available from the corresponding author on reasonable request.

\section{Declarations}

\section{Ethics approval and consent to participate}

Subjects (or their advocates) have given their written informed consent. The study protocol was approved by the Research Ethics Committee in Universidad El Bosque (012-2016) and was conducted ethically in accordance with the World Medical Association Declaration of Helsinki.

\section{Consent for publication}

Not applicable.

\section{Competing interests}

The authors declare that they have no competing interests.

\section{Author details}

1 UNICA - Caries Research Unit, Research Department, Universidad El Bosque, Av. Cra. 9 No. 131 A - 02, 110121 Bogotá, Colombia. ${ }^{2}$ Research Group in Gerodontology, School of Dentistry, Universidad Nacional de Colombia, Bogotá, Colombia. ${ }^{3}$ Grupo de Virología, Vicerrectoría de Investigaciones, Universidad El Bosque, Bogotá, Colombia. 
Received: 7 October 2020 Accepted: 26 February 2021

Published online: 23 March 2021

\section{References}

1. United Nations. World Population Ageing 2017 [Internet]. New York; 2017 [cited 2019 June 2]. https://www.un.org/en/development/desa/popul ation/theme/ageing/WPA2017.asp.

2. República de Colombia - Ministerio de Salud y Protección Social. IV Estudio Nacional de Salud Bucal ENSAB IV: Situación en Salud Bucal. Ministerio de Salud y Protección Social. Bogotá; 2015. https://www. researchgate.net/publication/306604640_IV_ESTUDIO_NACIONAL_DE SALUD_BUCAL_ENSAB_IV_Metodologia_y_Determinacion_Social_de_ la_Salud_Bucal.

3. Steele JG, Sheiham A, Marcenes W, Fay N, Walls AW. Clinical and behavioural risk indicators for root caries in older people. Gerodontology. 2001;18(2):95-101. https://doi.org/10.1111/j.1741-2358.2001.00095.x.

4. Petelin M, Cotič J, Perkič K, Pavlič A. Oral health of the elderly living in residential homes in Slovenia. Gerodontology. 2012;29(2):e447-57. https:// doi.org/10.1111/j.1741-2358.2011.00497.x.

5. Montal S, Tramini P, Triay J-A, Valcarcel J. Oral hygiene and the need for treatment of the dependent institutionalised elderly. Gerodontology. 2006:23(2):67-72. https://doi.org/10.1111/j.1741-2358.2006.00111.x.

6. Serrano-Urrea R, Gómez-Rubio V, Palacios-Ceña D, Fernández-de-LasPeñas C, García-Meseguer MJ. Individual and institutional factors associated with functional disability in nursing home residents: An observational study with multilevel analysis. PLOS ONE. 2017;12(8):e0183945. https://doi.org/10.1371/journal.pone.0183945.

7. Tonetti MS, Bottenberg P, Conrads G, Eickholz P, Heasman P, Huysmans $\mathrm{M}-\mathrm{C}$, et al. Dental caries and periodontal diseases in the ageing population: call to action to protect and enhance oral health and well-being as an essential component of healthy ageing — consensus report of group 4 of the joint EFP/ORCA workshop on the boundaries be. J Clin Periodontol. 2017:44(Suppl 18):135-44. https://doi.org/10.1111/jcpe.12681.

8. Nicolau B, Srisilapanan P, Marcenes W. Number of teeth and risk of root caries. Gerodontology. 2000;17(2):91-6. https://doi.org/10.1111/j.17412358.2000.00091.x

9. Ritter AV, Shugars DA, Bader JD. Root caries risk indicators: a systematic review of risk models. Community Dent Oral Epidemiol. 2010;38(5):38397. https://doi.org/10.1111/j.1600-0528.2010.00551.x

10. Ritter AV, Preisser JS, Puranik CP, Chung Y, Bader JD, Shugars DA, et al. A predictive model for root caries incidence. Caries Res. 2016;50(3):271-8. https://doi.org/10.1159/000445445.

11. López R, Smith PC, Göstemeyer G, Schwendicke F. Ageing, dental caries and periodontal diseases. J Clin Periodontol. 2017;44:S145-52. https://doi. org/10.1111/jcpe.12683.

12. Thomson WM, Broadbent JM, Foster Page LA, Poulton R. Antecedents and associations of root surface caries experience among 38-year-olds. Caries Res. 2013;47(2):128-34. https://doi.org/10.1159/000345078.

13. Hayes M, Da Mata C, Cole M, McKenna G, Burke F, Allen PF. Risk indicators associated with root caries in independently living older adults. J Dent. 2016:51:8-14. https://doi.org/10.1016/j.jdent.2016.05.006.

14. Carvalho TS, Lussi A. Age-related morphological, histological and functional changes in teeth. J Oral Rehabil. 2017;44(4):291-8. https://doi.org/ 10.1111/joor.12474

15. Martignon S, Pitts NB, Goffin G, Mazevet M, Douglas GVA, Newton JT, et al. CariesCare practice guide: consensus on evidence into practice. Br Dent J. 2019;227(5):353-62. https://doi.org/10.1038/s41415-019-0678-8.

16. WHO/FAO Expert Consultation. Diet, nutrition and the prevention of chronic diseases. Geneva; 2003 [cited 2020 June 23]. https://apps.who. int/iris/bitstream/handle/10665/42665/WHO_TRS_916.pdf;jsessionid= 515AEC7856CA2FAD0A77E51C8F129D27? sequence $=1$

17. Moynihan P. Evidence for setting a recommended threshold for intake. Adv Nutr. 2016;7(1):149-56. https://doi.org/10.3945/an.115.009365.

18. Katz RV. Clinical signs of root caries: measurement issues from an epidemiologic perspective. J Dent Res. 1990;69(5):1211-5. https://doi.org/10. $1177 / 00220345900690051801$.

19. World Health Organization. Oral health surveys; basic methods [Internet]. WHO. World Health Organization; 2013 [cited 2020 Oct 14]. http://www. who.int/oral_health/publications/9789241548649/en/.
20. Pitts NB, Ekstrand KR, ICDAS Foundation International Caries Detection and Assessment System (ICDAS) and its International Caries Classification and Management System (ICCMS) — methods for staging of the caries process and enabling dentists to manage caries. Community Dent Oral Epidemiol. 2013:41(1):e41-52. https://doi.org/10.1111/cdoe.12025.

21. Burt BA, Kolker JL, Sandretto AM, Yuan Y, Sohn W, Ismail Al. Dietary patterns related to caries in a low-income adult population. Caries Res. 2006;40(6):473-80. https://doi.org/10.1159/000095645.

22. Silva M, Hopcraft M, Morgan M. Dental caries in Victorian nursing homes. Aust Dent J. 2014;59(3):321-8. https://doi.org/10.1111/adj.12188.

23. Rojas Cuadros DF, Mendoza Sichacá AC. Descripción y análisis del servicio que prestan algunos hogares geriátricos a los adultos mayores en Bogotá. Universidad de La Salle; 2017. https://ciencia.lasalle.edu.co/cgi/ viewcontent.cgi?article $=1226 \&$ context=administracion_de empresas.

24. ICDAS Foundation. Homepage. 2014. https://www.iccms-web.com/.

25. Ekstrand K, Martignon S, Holm-Pedersen P. Development and evaluation of two root caries controlling programmes for home-based frail people older than 75 years. Gerodontology. 2008;25(2):67-75. https://doi.org/10. 1111/j.1741-2358.2007.00200.x.

26. Pinzón-Pulido SA, Gil-Montoya JA. Validation of the Assessment Index of Oral Health in Geriatrics in an institutionalized geriatric population in Granada. Rev Esp Geriatr Gerontol. 1999;34(5):273-82.

27. Bratthall D, Hansel PG. Cariogram—a multifactorial risk assessment model for a multifactorial disease. Community Dent Oral Epidemiol. 2005;33(4):256-64. https://doi.org/10.1111/j.1600-0528.2005.00233.x.

28. Martignon S, Bautista-Mendoza G, González-Carrera M, Lafaurie-Villamil G, Morales V. Parents/caregivers of small children. Rev Salud Publica Bogota. 2008;10(2):308-14. https://doi.org/10.1590/s0124-0064200800 0200011

29. Hayes M, Da Mata C, McKenna G, Burke FM, Allen PF. Evaluation of the Cariogram for root caries prediction. J Dent. 2017:62:25-30. https://doi. org/10.1016/j.jdent.2017.04.010.

30. Gutiérrez Quiceno B, Calzada Gutiérrez MT, Fandiño-Losada A. Cultural adaptation and validation of the Geriatric Oral Health Assessment Index - GOHAl_Colombian version. Colomb medica (Cali, Colomb. 2019:50(2):102-14. https://doi.org/10.25100/cm.v50i2.3999.

31. Altman DG. Practical Statistics for Medical Research. In: Chapman \& Hall. 1991 . p. 419-26. https://es.scribd.com/doc/273959883/Douglas-G-Altman-Practical-Statistics-for-Medical-Research-Chapman-Hall-CRC-1991.

32. Hsieh C, Maisonneuve P, Boyle P, Macfarlane GJ, Robertson C. Analysis of quantitative data by quantiles in epidemiologic studies: classification according to cases, noncases, or all subjects? Epidemiology. 1991;2(2):137-40. https://doi.org/10.1097/00001648-199103000-00008.

33. Bernabé $E$, Sheiham A. Age, period and cohort trends in caries of permanent teeth in four developed countries. Am J Public Health. 2014;104(7):e115-21. https://doi.org/10.2105/AJPH.2014.301869.

34. Suzuki S, Onose Y, Yoshino K, Takayanagi A, Kamijo H, Sugihara N. Factors associated with development of root caries in dentition without root caries experience in a 2-year cohort study in Japan. J Dent. 2020;95:103304. https://doi.org/10.1016/j.jdent.2020.103304.

35. Carvalho TS, Lussi A. Assessment of root caries lesion activity and its histopathological features. Monogr Oral Sci. 2017;26:63-9. https://doi.org/10. $1159 / 000479346$.

36. Fure S, Zickert I. Root surface caries and associated factors. Eur J Oral Sci. 1990;98(5):391-400. https://doi.org/10.1111/j.1600-0722.1990.tb00990.x.

37. Ismail Al, Pitts NB, Tellez M, Banerjee A, Deery C, Douglas G, et al. The International Caries Classification and Management System (ICCMSTM) an example of a caries management pathway. BMC Oral Health. 2015;15(1):S9. https://doi.org/10.1186/1472-6831-15-S1-S9.

38. Christensen LB, Bardow A, Ekstrand K, Fiehn N-E, Heitmann BL, Qvist V et al. Root caries, root surface restorations and lifestyle factors in adult Danes. Acta Odontol Scand. 2015;73(6):467-73. https://doi.org/10.3109/ 00016357.2014 .986753

39. República de Colombia - Ministerio de Salud y Protección Social. Resolución 3280 de 2018 - Nuevas Rutas Integrales de Atención en Salud. Ministerio de Salud y Protección Social, Resolución 32802018 p. 1-348. https://www.asivamosensalud.org/politicas-publicas/normatividad-resol uciones/prestaciones-de-servicios-de-salud/resolucion-3280-de.

40. Marin Zuluaga DJ, Ferreira J, Gil Montoya JA, Willumsen T. Oral health in institutionalised elderly people in Oslo, Norway and its 
relationship with dependence and cognitive impairment. Gerodontology. 2012;29(2):e420-6. https://doi.org/10.1111/j.1741-2358.2011.00490.x.

41. Shao Z, Guo X, Zhang Q, Bronkhorst EM, Zou D, Creugers NHJ. Masticatory efficiency in patients with partially dentate dentitions. J Dent. 2018;75:41-7. https://doi.org/10.1016/j.jdent.2018.05.005.

42. Ribeiro Gaião L, Leitão de Almeida ME, Bezerra Filho JG, Leggat P, HeukeIbach J. Poor dental status and oral hygiene practices in institutionalized older people in northeast Brazil. Int J Dent. 2009;2009:846081. https://doi. org/10.1155/2009/846081.

43. Nelson SLP, Ramakrishnan V, Nietert PJ, Kamen DL, Ramos PS, Wolf BJ. An evaluation of common methods for dichotomization of continuous variables to discriminate disease status. Commun Stat Theory Methods. 2017;46(21):10823-34. https://doi.org/10.1080/03610926.2016.124878.

44. Peres MA, Macpherson LMD, Weyant RJ, Daly B, Venturelli R, Mathur $\mathrm{MR}$, et al. Oral diseases: a global public health challenge. Lancet. 2019;394(10194):249-60. https://doi.org/10.1016/S0140-6736(19) 31146-8.

\section{Publisher's Note}

Springer Nature remains neutral with regard to jurisdictional claims in published maps and institutional affiliations.
Ready to submit your research? Choose BMC and benefit from:

- fast, convenient online submission

- thorough peer review by experienced researchers in your field

- rapid publication on acceptance

- support for research data, including large and complex data types

- gold Open Access which fosters wider collaboration and increased citations

- maximum visibility for your research: over 100M website views per year

At BMC, research is always in progress.

Learn more biomedcentral.com/submissions 